\title{
The Reality of Using E-Learning in Arab Schools in Israel from the Parents' Point of View
}

\author{
Prof. linda fuad safoury Dr. Nadia Hassan Ghalia \\ Dr. Ahlam Mahmood Darawsheh
}

\begin{abstract}
This study aimed at identifying the reality of using e-learning in Arab schools in Israel from the parents' point of view. A total of eighty eight (88) questionnaires were distributed through e- mail and Whats App application, and one eighty two (82) were completed and returned. The questionnaire consisted of (44) items divided into two fields (the reality of using of electronic curricula, and the reality of electronic technical facilities), and questionnaire applied to a random sample consisted of (82) parents, during the first academic semester 2020/2021. The study findings showed that the reality of using electronic curricula in Arab schools in Israel from the parents' point of view came in medium degree. Also the findings showed that the reality of the electronic technical facilities used in Arab schools in Israel from the parents' point of view came in medium degree.
\end{abstract}

Keywords: E-Learning, Arab Schools, Israel, Parents.

DOI: $10.7176 / \mathrm{IKM} / 11-1-04$

Publication date: January $31^{\text {st }} 2021$

\subsection{Introduction}

Nowadays, technology has become one of the best means for teaching and learning with or without school premises. This technology allowed the use of instructional methods to improve the quality of education and students' academic performances (Olaniran, 2017). E-Learning is fast progressing scientific field proposing novel and specific approaches in a range of domains. It is well established practice in universities, schools and organizations for delivering interactive, adaptive and flexible training, taking advantage of contemporary and emerging technologies (Ivanova, 2020).

E-learning meant to transform the old methods and approaches of curriculum implementation in order to bring about certain changes in the behavior of the learners as well as the extent in which the changes take place (Akanbi, 2020). E-learning is the use of electronic technology to deliver, support and enhance teaching and learning (Olson, Codde \& deMaagd, 2011). It includes the use of new multimedia technologies and the Internet to improve the quality of learning, by facilitating access to resources and services as well as remote exchanges and collaboration (Bada, Asianzu, Lugemwa, Namataba \& Milburga, 2020). E-learning is considered as an important component of enhancing teaching and learning processes by Higher Learning Institutions. In the context of teaching and learning, eLearning encompasses the use of information, computers and technology to enhance communication in distance- learning (Innocent \& Masue, 2020).

Nowadays, one big part of educational process benefits of the usage of information technologies through different forms of E- Learning and it does not matter the type of educational organization where it is provided: from universities and schools to small training organizations. Also, information technologies are used to support any form of knowledge delivery: in fully online universities and programs, distance and blended-learning programs and courses, face-to-face lectures and classes (Ivanova, 2020). E-learning (digital learning) has various benefits for both students and teachers. For a student, in e-learning assessments students may be able to give faster feedback concerning their comprehension. Besides the use of virtual reality and visualizations. On the other hand through e-learning, in asynchronous classrooms students can to faculties or schools anytime and anywhere (Shaikh, Umrani, Jumani \& Laghari, 2019).

There are four types of e-learning, according to Al-Sharqawi (2015):

- Multimedia and hypermedia strategy: that can be used in analyzing and developing electronic concepts and skills and displaying educational content through them instead of boring traditional methods.

- Electronic scientific statement: The scientific statement can be used in the performance of skills in front of the student after preparing their steps electronically on electronic media to confirm the scientific information by showing the implementation steps.

- Electronic scientific experimentation: This strategy can be used to allow students the opportunity to experiment on their own in performing the required skills electronically while providing feedback.

- Electronic training: E-training is used to train students to master the concepts and skills of education and elearning, in order to be an aid supported by scientific experimentation, so that the student can try himself after his training.

E-learning is very importance, as many workers in the educational field place great hopes on the role it can play in the development of the educational system. As e- learning, with its use of technologies, devices, tools, materials, educational situations and effective participation by students, works to change the teacher's role from a 
single source of information to a guide for the student, and an assistant to him in self-learning. At the same time, it works to change the student's role from receiving information to being an interlocutor, analyst, critic and producer of information (Al-Khatib, 2013), therefore, technology in the educational field has become an absolute necessity due to the multiplicity of its fields, tasks and uses, it has also become an essential part in performing tasks at the individual and institutional level, and thus it is no longer a luxury or an alternative in the fundamentals of administrative, technical and financial work (Al-Kindi, 2018). In light of the development of administrative and technical work in schools as a result of technical development, the need has become urgent to take advantage of the advantages of modern technologies in developing educational system (Manyike, 2017).

For the success of the application of e-learning and its activation, teachers must be trained on the effective use of tools, software and electronic educational platforms, and providing infrastructure and technical equipment such as computers, laboratories, and Internet networks, this makes the provision of human and technical requirements a crucial factor in the success of e-learning and education (Al-Shuraida, 2018), and computers and the associated use of the various software programs often associated with the use of the Internet must be provided, as the use of the Internet has made a huge qualitative leap in the field of learning and education, easy access to educational resources, and saved time and effort (Al-Shammari, 2019). E-learning helps solving the problem of knowledge explosion, the increasing demand for education, expanding opportunities for students to learn by depending on themselves, and being able to train and educate students and qualify them without leaving their houses. E-learning holds broad access to knowledge and expert resources, which provides individuals with many educational opportunities. E-learning also helps to face the challenges of crowded classrooms, the lack of capabilities, and places, and the inability to provide an atmosphere conducive to creativity, and the inability to take into account individual differences between learners (Qashmar, 2017).

The tools of modern technology that have recently spread at the level of universities, schools and teachers have enabled them to design and display their lessons effectively, by including pictures, videos, presentations, and an Internet connection that provides an opportunity for direct research. These technologies facilitate the teacher's task and make him more creative, and allow the opportunity to store and retrieve lessons quickly, in addition to processing stored data, reaching results, as well as providing an opportunity to bring the outside world into the classroom (Canadian Teacher Magazine, 2014). E-learning also contributes in facilitating effective designing lessons, by including pictures, videos, and presentations, in addition to an Internet connection that provides an opportunity for direct research. E-learning provided the opportunity to quickly store and retrieve lessons, as well as process stored data, and find results (Canadian Teacher Magazine, 2014).

In addition to the fact that one of the most important features of asynchronous e-learning is its ability to spread education to all school students who are in any subordinate location, and the means and methods used to transfer information to students and interact with it are varied, and the sources of knowledge available to students are varied, and asynchronous e-learning is an active interactive method in education, it relies on new methods that are not used in traditional education systems, and one of its advantages is its flexibility in teaching the curriculum and implementing it, as the learner can receive education at anytime and anywhere, and asynchronous e-learning reduces the cost of education (Desmond, 1995). Asynchronous e-learning mainly depends on the idea of programmed education in which the student can learn by himself according to his own abilities. Education is not done directly between the teacher and his students, and the communication between the two parties to the educational process is using multiple means such as the Internet and educational platforms, and it also depends on building courses electronically, The curriculum will include all educational methods for presenting explanations, and the curriculum will be transformed into an electronic material (Jalali, 2011). Also, one of the most important motives for adopting asynchronous e-learning is the need to take into account individual differences because it depends on self-learning, meeting the psychological needs of students, and increasing motivation to learn (Khamis, 2008.)

Asynchronous e-learning is practiced through an educational institution that is planning, preparing, and implementing for it, and is based on intermittent separation between the teacher and the learner, and it requires multiple technological means, and it is also necessary for the learner to have motivation. Education opportunities are without geographical boundaries, and education takes the characteristic of flexibility and openness, as it does not impose restrictions on the place and time to start and finish the study (Abu Ghraib, 2004).

In the education field, many developments can be seen too, and the concept of 'readiness' is one of the most important key factors in E-learning. As readiness makes learning easier and this makes e-learning becomes easier too (Erdugan, 2020). These facts impose on all educational systems to investigate the reality of actual readiness to implement e-learning, especially the readiness of technical educational facilities and electronic curricula, so the current study came to investigate the reality of using e-learning in Arab schools in Israel from the parents' point of view.

\subsection{Problem and questions of the study}

The World Health Organization (WHO) declared that COVID-19 is a global emergency on January 2020, and a 
global pandemic on March 2020. Currently, COVID-19 is affecting 213 countries and territories (WHO, 2020). In response to COVID-19, several countries have applied strict social distancing measures and a lockdown policy. Obviously, this pandemic has had a tremendous impact on schools, students and teachers. As of March, 2020, 46 countries in five different continents have declared school closures and 26 of these countries have fully closed schools nationwide (Huang, Liu, Tlili, Yang, \& Wang, 2020).

Indeed, the COVID-19 virus sweeps the world and lead to dramatic changes in our lives and in how we deliver education. Schools and universities have been forced to embrace digital delivery modes virtually overnight, and students now face an online and/or blended educational experience for many months to come. We ask ourselves: how much of this digital transformation will last? How can we ensure that the lessons we are currently learning about good practice in the use of technology will be developed and maintained beyond this crisis? (Borthwick \& Plutino, 2020), Notwithstanding the key role played by e-learning in improving the teaching and learning process, there is the problem of inadequate knowledge about using e-learning in teaching students in school (Innocent \& Masue, 2020). And based on the results of many studies that showed that there are many obstacles in adopting elearning in schools, such as the study of Meirovitz \& Aran (2020), Apostolou (2020), Bigirwa, Ndawula, Naluwemba (2020), Akanbi (2020), Alqahtani \& Rajkhan (2020), Siron, Wibowo, \& Narmaditya (2020), Hariyanto, Triyono \& Kohler (2020), Mailizar, Maulina \& Bruce (2020), Innocent \& Masue (2020) and Shdaifat, Shdaifat \& Khateeb (2020).

this formed a strong motivation for the researcher to investigate the reality of using e-learning in Arab schools in Israel from the parents' point of view. More specifically, the main question was: What is the reality of using elearning in Arab schools in Israel from the parents' point of view? The following questions are divided into:

\section{Sub-questions}

1. What is the reality of using electronic curricula in Arab schools in Israel from the parents' point of view?

2. What is the reality of the electronic technical facilities used in Arab schools in Israel from the parents' point of view?

\subsection{Importance of the study}

The importance of this study emerged from the urgent need to identify the reality of using e-learning in Arab schools in Israel from the parents' point of view because of the rapid technical, social and educational changes in Israel, so the importance of this study comes from its results, and the impact of these results on those in charge of education in Israel, and the importance of this study can be shown as follow:

\section{Theoretical importance}

- Enrich the theoretical aspect regarded the using of e-learning in Arab schools in Israel, as the researcher hopes that the study results contribute in enriching Israel library in this field.

- This study is expected to open up new doors in the field of using the e-learning in Arab schools in Israel, to conduct new studies to promote or deny the findings of this study.

\section{Applied practical aspect:}

- Providing a feedback about the using of e-learning in Arab schools in Israel to the educational leaders.

- It hoped to benefit from the findings and recommendations of this study the researchers and those interested in using the e-learning in Arab schools in Israel.

- It is hoped that this study findings help decision-makers in Israel in identifying the reality of using e-learning in Arab schools in Israel, to help them in making appropriate decisions to improve the educational process.

\subsection{Terminology}

The study adopting identifying the following terms:

E- learning: are defined as: “

The researcher defines E- learning in this study procedurally with the electronic facilities, methods and procedures practiced by Arab school in Israel within two basic dimensions: (technical, curriculum) that will be measured by the tool prepared to measure it.

\subsection{Study limitations}

The results of this study are determined by the nature of the sample and the tool of the study, as follows:

- The sample: it is limited to the parents' point of view.

- The temporal boundary: it is limited to the academic year 2020- 2021.

- Objective limit: identifying the reality of using e-learning in Arab schools in Israel from the parents' point of view. 


\subsection{Variables}

The study includes three dependent variables, namely:

- The reality of using electronic curricula in Arab schools in Israel from the parents' point of view.

- The reality of the electronic technical facilities used in Arab schools in Israel from the parents' point of view.

\section{Previous studies}

The current study adopts showing some previous studies, as follow:

The study of Bigirwa, Ndawula, Naluwemba (2020) aimed at ascertaining the relevance of on-line quality management in improve e-Learning adoption in midwifery schools in Uganda. It used an explanatory sequential mixed methods design to ascertain if online quality management was significant at improving e-learning adoption and the on-line quality traits which would be implemented by midwifery schools to improve e-learning adoption. Data collection was conducted in two phases, the first entailed quantitative data collection and analysis to determine if on-line quality management was significant to e-learning adoption. The second embraced a qualitative data collection and analysis to ascertain the detailed traits of on-line quality management relevant to e-learning adoption. Linear regression analysis established on-line quality management had influence on e-learning adoption $(\mathrm{p}=0.000)$. On-line quality management accounted for $55.5 \%$ of the variance in e-learning adoption with a strong positive statistically significant relationship, and its salient traits included; Compact Disc, Read-Only-Memory materials meets the expectation of users, collaborative improvement of on-line quality, Learning Management System meets expectations of users, providing the best on-line experience, e-learning program being described as an excellent on-line learning experience, and guidelines for improving on-line quality. Midwifery schools therefore have to focus on the six most relevant traits of on-line quality management if they are to improve e-learning adoption.

Akanbi (2020) study aimed at examining the utilization as well as the availability of E-learning facilities in the teaching of senior school physics in Ilorin, Nigeria. The study was a survey type and all physics teachers constitute the population. A total of 60 teachers was sampled for the study. Multi-stage sampling technique was adopted in the selection of respondents. Simple random sampling technique was used to select 20 out of 35 secondary schools. Two structured checklists were used to collect data. The finding revealed that printers, photocopying machine, desktop computers, laptop computers, Android phones, electronic typewriters and scanners were available, E-learning facilities were not utilized, there is no significant difference in the utilization of E-learning facilities for teaching physics based on teachers' qualifications and experience. It was then recommended that physics teachers should be given proper training on how to use as well as maintain E-learning facilities in their various schools in order to equip them with the necessary skills, knowledge and values that will enable them optimize teaching in a fast changing world.

Alqahtani \& Rajkhan (2020) study aimed at identifying the critical success factors for E-learning during COVID-19 using the multi-criteria Analytic Hierarchy Process (AHP) and Technique for Order Preference by Similarity to Ideal Solution (TOPSIS) techniques to enhance the educational process. Data were generated by interviewing 69 E-learning managers in educational institutions during COVID-19 based on defined evaluation criteria and E-learning approaches through several channels. We found that technology management, support from management, increased student awareness to use E-learning systems, and demanding a high level of information technology from instructors, students, and universities were the most influential factors for E-learning during COVID-19. Among the five learning systems, blended learning was the most suitable learning system to practice. These results demonstrated that, regardless of how extraordinary the technology is in an educational institution, the readiness of E-learning execution played a large role in boosting the educational process during the COVID19 pandemic.

Siron, Wibowo, \& Narmaditya (2020) study aims to examine factors affecting the use of e-learning during the COVID-19 pandemic in Indonesia. This survey study utilized a quantitative approach to understand the relationship variables by using SEM-PLS. An online questionnaire was distributed to collect information from respondents. A total of 250 questionnaires were gathered, and 210 responses can be used for further analysis. The findings indicate that the students' intention in using e-learning was determined by several variables, including perceived enjoyment, students experience, computer anxiety, and perceived self-efficacy. These findings also confirm that both perceived ease of use and perceived usefulness can explain the students' intention in utilizing elearning. The results provide an implication toward the importance of understanding the factors of e-learning adoption and how students can perceive e-learning as the response of the COVID-19 pandemic.

Innocent \& Masue (2020) study aims to discuss the applicability of e-learning in Higher Learning Institutions (HLIs) in Tanzania using three selected universities in the Morogoro Region. Data were collected using questionnaires and interviews among a sample 90 respondents, who were selected using simple random and purposive sampling techniques. Data were analysed through descriptive statistics and results presented using frequency and mean statistics. The results revealed that there is limited applicability of e-learning in the three HLIs studied. The inadequate applicability of e learning is attributed to poor attitude, lack of skills among the users and 
insufficient ICT infrastructure.

Hariyanto, Triyono \& Kohler (2020) aims at evaluating the usability of personalized adaptive e-learning system that has been developed based on students' learning style and initial knowledge level. The study involved 62 Computer Network students in one of the public vocational secondary schools in Yogyakarta, Indonesia. To measure the usability, the USE Questionnaire, which consists of four indicators (usefulness, ease of use, ease of learning, and satisfaction) represented by 30 questions with four possible Likert scale options, was distributed to the students. The research finding indicates at first the usability of the adaptive e-learning system for the students was well accepted in all aspects of usability. Next, the multiple linear regression result showed that the variables usefulness, ease of use, and ease of learning simultaneously influence satisfaction. Lastly, the regression results also revealed that the variables usefulness and ease of use partially influence satisfaction, while the variable ease of learning does not.

Mailizar, Maulina \& Bruce (2020) noted that School closures in Indonesia during the COVID-19 pandemic have left 45.5 million school students and 3.1 million teachers dependent on online teaching and learning. Online teaching and learning are an unprecedented experience for most teachers and students; consequently, they have a limited experience with it, so this study examines the views of secondary school mathematics teachers on Elearning implementation barriers during the COVID-19 pandemic at four barrier levels, namely teacher, school, curriculum and student. Furthermore, it assesses the relationship between barrier levels with teachers' demographic background. Data was collected through an online questionnaire, involving 159 participants from lower and upper secondary schools in Indonesia. The findings of this study suggest that student level barrier had the highest impact on e-learning use. In addition, the student level barrier showed strong positive correlation with the school level barrier and curriculum level barrier. The study showed that teachers' backgrounds had no impact on the level of barriers. This study stimulates further discussion on the way to overcome e-learning barriers whilst simultaneously maximizing benefits of E-learning during this pandemic and beyond it by highlighting the importance of students' voices.

The study of Shdaifat, Shdaifat \& Khateeb (2020) aimed to explore the reality of using E-Learning applications in vocational education courses during COVID 19 crisis in Jordan from the perspective of vocational education teachers. It aimed to explore the way students interact with e-learning applications in this regard. It aimed to explore the challenges associated with using E-Learning applications in this regard. A sample was selected. It consists from 60 vocational education teachers. These teachers were selected from the primary public schools in Jordan. A three-part questionnaire was used. It was found that respondents have negative attitudes towards using E-Learning applications in vocational education courses during COVID 19 crisis in Jordan. It was found that the severity of the challenges associated with using E-Learning applications in this regard is high. In the light of the study's results, several recommendations were proposed. For instance, the researchers recommend providing vocational education teachers at Jordanian schools with training courses about the way of using ELearning applications.

The study of Meirovitz \& Aran (2020) aims to investigate the introduce of a digital thinking skills (DTS) theoretical model (DTSM) that could support and enhance digital instruction best practices in schools in Israel. The researchers used a mixed-methods approach. The respondents represent diverse cultural, linguistic, pedagogical, and social heritages. The study provides a theoretical model developed by Eshet-Alkalai and Aviram that could impact subsequent digital teaching in schools. The highly accessible model may help teachers understand the cognitive learning outcomes that derive from frequently used digital tools. The study findings indicate that teachers do not have a pedagogical concept of digital thinking skills, though many believe such skills might have a positive effect on their learners' achievements. School culture plays a key role in effective DI delivery. Teachers want better in-service IT instruction.

Apostolou (2020) study aimed to examine the extent to which the level of technological equipment affects the integration of the Information and Communication Technologies (ICT) in Greek high school science teaching. The limited ICT infrastructure environment, with only one computer-projector system available and access to the internet ("PC-VP" environment), is compared to the high level ICT environment ("1:1" environment) where, in addition to the computer-projector system, each student has access to a computer and the internet. It is a study relying on a relatively small dataset derived from student answers to a questionnaire aiming to determine the degree to which some of the "expected" ICT benefits reach the students. The level of ICT integration is judged by the degree to which the ICT benefits reach the students. That is, the more the ICT benefits reach the students, the better - or the greater - the ICT integration is. The participants were eighty nine, 14-year-old students who belonged in four different classes and the teacher who taught Physics in those classes. The SPSS non-parametric "Man-Whitney U Test" test was used to compare the statistical distributions of student answers. The results show that, when the applied teaching approach is used, the ICT integration is equally successful in both environments. This questions the idea of investing in "1:1" environments in the Greek public schools where less student centered and inquiry oriented teaching approaches are the norm. It also highlights the importance of the specific teaching approach as an ICT integration tool in "PC-VP" environments that still exist in most Greek schools. 


\subsection{Methodology}

The study was a descriptive survey type as it aimed at investigating the reality of using e-learning in Arab schools in Israel from the parents' point of view, so the study used the descriptive survey method which regarded suitable for this study.

\subsection{Study participants}

The population for the study comprised all parents' school students in Israel. A total of eighty eight (88) questionnaires were distributed through e- mail and Whats App application, and one eighty two (82) were completed and returned. The response rate for questionnaires was therefore 93.2 percent. The above response rate was considered adequate enough to provide a rational judgment to make a case for any scientific recommendations or observations.

To investigate the degree of using entrepreneurship strategies in higher education institutions in Israel from the viewpoint of their employees, a questionnaire was developed by the researcher.

\subsection{Validity of the study tool}

To ascertain the validity of the study tool, content validity was used by viewing the questionnaire to (12) arbitrators of the faculty members who specialize in educational administration, so as to take their opinions on the content of the tool, and the adequacy of paragraphs, and the need to modify or delete any paragraph, and any comment they think it is necessary, in the light of the observations of the arbitrators, some items were modified, but no item deleted, and the researcher found that the paragraphs were correlated to their dimensions, as the agreement degree between the arbitrators reached (90\%), and this percentage is regarded suitable for the purposes of this study.

\subsection{Reliability of the study tool}

Research tool reliability was assured reliability by using the (Test- retest), and by applying it on (16) parents from outside the research sample, and Pearson correlation coefficient was calculated, and the value of reliability coefficient was (0.94), and this is an acceptable value for the purposes of the Research.

The reality of using e-learning in Arab schools in Israel from the parents' point of view was determined by dividing the degrees to three levels (high, medium, low) based on the following equation:

The highest value - the lowest value $/$ number of levels $=(5-1) / 3=4 / 3=1.33$.

Thus it was adopted the following Criterion to determine the reality of using e-learning in Arab schools in Israel from the parents' point of view:

- Low degree: represent grades between (1-2.33).

Medium degree: represent grades between (2.34- 3.67).

.( High degree of exercise: represent grades between (3.68- 5.00).

\subsection{Statistical treatment}

To answer the questions of the study the appropriate statistical methods were used as follow:

- To answer the first and second question, the averages and standard deviations were used.

\section{Study results and discussion}

The study presents the findings that reached through the respondents of the sample to the questions, as follows:

4.1. Findings related to the first question that stated: "What is the reality of using electronic curricula in Arab schools in Israel from the parents' point of view?"

What is the reality of using electronic curricula in Arab schools in Israel from the point of view of parents?

To answer this question, arithmetic averages and standard deviations were calculated for is the reality of using electronic curricula in Arab schools in Israel from the parents' point of view for the dimension as a whole, and for each of its items, and Table (1) shows that. 
Table (1): Arithmetic averages, standard deviations, and ranks of the reality of using electronic curricula in Arab schools in Israel from the parents' point of view for the field in general, and for each of its items, arranged in descending order.

\begin{tabular}{|c|c|c|c|c|c|}
\hline no. & The question & $\begin{array}{l}\text { arithmetic } \\
\text { average }\end{array}$ & $\begin{array}{c}\text { standard } \\
\text { deviation }\end{array}$ & rank & degree \\
\hline 1 & $\begin{array}{l}\text { The curriculum has been computerized to be taught } \\
\text { according to distance learning whenever required. }\end{array}$ & 4.32 & 0.28 & 1 & high \\
\hline 5 & Asynchronous electronic learning is used. & 4.32 & 0.32 & 2 & high \\
\hline 2 & $\begin{array}{l}\text { Most of the lessons are implemented according to } \\
\text { distance learning. }\end{array}$ & 4.11 & 0.55 & 3 & high \\
\hline 3 & Lessons are evaluated according to distance learning. & 4.01 & 0.61 & 4 & high \\
\hline 8 & $\begin{array}{l}\text { Students are subjected to tests based on distance } \\
\text { learning. }\end{array}$ & 3.94 & 0.52 & 5 & high \\
\hline 7 & Monitoring of students 'completion of their homework. & 3.81 & 0.39 & 6 & high \\
\hline 10 & The lesson software is updated continuously. & 3.71 & 0.42 & 7 & high \\
\hline 9 & $\begin{array}{l}\text { Students are evaluated according to their achievement } \\
\text { on the educational platforms. }\end{array}$ & 3.65 & 0.49 & 8 & medium \\
\hline 16 & The computerized lessons include auditory stimuli. & 3.55 & 0.54 & 9 & medium \\
\hline 12 & $\begin{array}{l}\text { Students can return to lessons that they did not } \\
\text { understand at any time. }\end{array}$ & 3.32 & 0.47 & 10 & medium \\
\hline 11 & Students' lessons are reviewed periodically. & 3.08 & 0.57 & 11 & medium \\
\hline 15 & Computerized lessons include visual stimuli. & 3.05 & 0.61 & 12 & medium \\
\hline 4 & Concurrent e-learning is used. & 2.99 & 0.52 & 13 & medium \\
\hline 17 & $\begin{array}{l}\text { The student can communicate with the teacher } \\
\text { electronically when required. }\end{array}$ & 2.98 & 0.67 & 14 & medium \\
\hline 21 & $\begin{array}{l}\text { The electronic programs provide feedback to students } \\
\text { as needed. }\end{array}$ & 2.94 & 0.39 & 15 & medium \\
\hline 13 & Parents can participate in the performance assessment. & 2.87 & 0.38 & 16 & medium \\
\hline 14 & $\begin{array}{l}\text { The student can assess himself according to the } \\
\text { software used. }\end{array}$ & 2.85 & 0.45 & 17 & medium \\
\hline 19 & $\begin{array}{l}\text { The electronic programs allow students to interact with } \\
\text { each other. }\end{array}$ & 2.69 & 0.62 & 18 & medium \\
\hline 18 & $\begin{array}{l}\text { Parents can contact the school administration online } \\
\text { when required. }\end{array}$ & 2.64 & 0.61 & 19 & medium \\
\hline 6 & $\begin{array}{l}\text { Students are given assignments as if they were in the } \\
\text { classroom. }\end{array}$ & 2.58 & 0.57 & 20 & medium \\
\hline 20 & The electronic software used enables peer evaluation. & 2.31 & 0.29 & 21 & low \\
\hline & $\begin{array}{c}\text { The whole degree } \\
\end{array}$ & 3.32 & 0.28 & \multicolumn{2}{|c|}{ medium } \\
\hline
\end{tabular}

It is noted from Table (1) that the reality of using electronic curricula in Arab schools in Israel from the parents' point of view came in medium degree, as the arithmetic average reached (3.32) with a standard deviation (0.28), and this result means that there are some obstacles faced by Arab school in implementing e- learning. It is noted also that item (1) came in the first rank, which states that "The curriculum has been computerized to be taught according to distance learning whenever required", with a mean (4.32), and a standard deviation (0.28), which means that the Arab school in Israel interest in technical development, and the constant endeavor to take advantage of the facilities provided by modern digital technologies. Therefore, the curriculum is computerized to be taught according to distance learning whenever required. This finding is agree with the findings of Bigirwa, Ndawula, Naluwemba (2020) study which showed that Learning Management System meets expectations of users, providing the best on-line experience, e-learning program being described as an excellent on-line learning experience, and guidelines for improving on-line quality. And with Akanbi (2020) study finding which revealed that printers, photocopying machine, desktop computers, laptop computers, Android phones, electronic typewriters and scanners were available, E-learning facilities were not utilized, there is no significant difference in the utilization of E-learning facilities for teaching physics based on teachers' qualifications and experience, and Alqahtani \& Rajkhan (2020) study that technology management, support from management, increased student awareness to use E-learning systems, and demanding a high level of information technology from instructors, students, and universities were the most influential factors for E-learning during COVID-19. Among the five learning systems, blended learning was the most suitable learning system to practice. These results demonstrated that, regardless of how extraordinary the technology is in an educational institution, the readiness of E-learning execution played a large role in boosting the educational process during the COVID-19 pandemic. 
Item (20) which states that "The electronic software used enables peer evaluation" came in the last rank, with an arithmetic mean (2.31) and a standard deviation (0.29), and in a low degree, this result means that the student cannot evaluate his colleague and benefit from the errors, and this result may be attributed to the fact that computerized curricula do not allow "peer evaluation," and evaluation is limited to the evaluation performed by the teacher only, which is done electronically through the available electronic platforms. This finding is agree with the findings of the study of Meirovitz \& Aran (2020) which revealed that teachers do not have a pedagogical concept of digital thinking skills, though many believe such skills might have a positive effect on their learners' achievements. School culture plays a key role in effective DI delivery. Teachers want better in-service IT instruction, and with the findings of the study of Apostolou (2020) that revealed, when the applied teaching approach is used, the ICT integration is equally successful in both environments. This questions the idea of investing in " $1: 1$ " environments in the Greek public schools where less student centered and inquiry oriented teaching approaches are the norm. It also highlights the importance of the specific teaching approach as an ICT integration tool in "PC-VP" environments that still exist in most Greek schools.

\subsection{Findings related to the first question that stated: "what is the reality of the electronic technical facilities used in Arab schools in Israel from the parents' point of view?"}

To answer this question, arithmetic averages and standard deviations were calculated for what is the reality of the electronic technical facilities used in Arab schools in Israel from the parents' point of view? For the dimension as a whole, and for each of its items, and table (2) shows that.

Table (2): Arithmetic averages, standard deviations, and ranks of the reality of the electronic technical facilities used in Arab schools in Israel from the parents' point of view? for the field in general, and for each of its paragraphs, arranged in descending order.

\begin{tabular}{|c|c|c|c|c|c|}
\hline no. & The question & $\begin{array}{l}\text { arithmetic } \\
\text { average }\end{array}$ & $\begin{array}{l}\text { standard } \\
\text { deviation }\end{array}$ & rank & degree \\
\hline 9 & $\begin{array}{l}\text { Schools use a system to save and store data } \\
\text { electronically. }\end{array}$ & 4.22 & 0.29 & 1 & high \\
\hline 20 & Schools use modern electronic devices. & 4.05 & 0.54 & 2 & high \\
\hline 8 & $\begin{array}{l}\text { The school leadership is technically qualified to use } \\
\text { modern technologies. }\end{array}$ & 4.01 & 0.39 & 3 & high \\
\hline 12 & $\begin{array}{l}\text { Schools use a technical communication system that } \\
\text { links the different administrative levels. }\end{array}$ & 3.98 & 0.36 & 4 & high \\
\hline 10 & $\begin{array}{l}\text { Schools use an ever-changing technical information } \\
\text { system. }\end{array}$ & 3.92 & 0.51 & 5 & high \\
\hline 5 & School leadership is flexible to accept technical change. & 3.88 & 0.72 & 6 & high \\
\hline 2 & The school's administrative staff is technically trained. & 3.87 & 0.48 & 7 & high \\
\hline 7 & $\begin{array}{l}\text { The school leadership is working on developing } \\
\text { electronic programs. }\end{array}$ & 3.87 & 0.50 & 8 & high \\
\hline 11 & $\begin{array}{l}\text { Schools use communication networks with modern } \\
\text { software in the school. }\end{array}$ & 3.84 & 0.54 & 9 & high \\
\hline 6 & $\begin{array}{l}\text { The school leadership has the necessary expertise to } \\
\text { draw up technical development plans. }\end{array}$ & 3.74 & 0.81 & 10 & high \\
\hline 3 & $\begin{array}{l}\text { The teachers in the school have the competence to } \\
\text { implement developmental technical programs. }\end{array}$ & 3.69 & 0.68 & 11 & high \\
\hline 14 & $\begin{array}{l}\text { Schools have the necessary facilities to operate modern } \\
\text { technologies. }\end{array}$ & 3.64 & 0.39 & 12 & medium \\
\hline 13 & $\begin{array}{l}\text { Schools use a technical information system attached to } \\
\text { needs of their employees. }\end{array}$ & 3.55 & 0.46 & 13 & medium \\
\hline 21 & $\begin{array}{l}\text { Schools use a technical communication system that } \\
\text { connects teachers with administration. }\end{array}$ & 3.39 & 0.49 & 14 & medium \\
\hline 22 & $\begin{array}{l}\text { Schools use an electronic system that provides } \\
\text { information about students. }\end{array}$ & 3.29 & 0.35 & 15 & medium \\
\hline 23 & $\begin{array}{l}\text { Schools use a communication system that connects } \\
\text { students with the administration electronically. }\end{array}$ & 3.09 & 0.45 & 16 & medium \\
\hline 19 & Schools use a high speed Internet. & 3.01 & 0.83 & 17 & medium \\
\hline 18 & $\begin{array}{l}\text { Schools use an electronic system to evaluate } \\
\text { performance. }\end{array}$ & 2.91 & 0.67 & 18 & medium \\
\hline 15 & $\begin{array}{l}\text { Schools use a communication system that connects } \\
\text { students with teachers electronically. }\end{array}$ & 2.85 & 0.61 & 19 & medium \\
\hline
\end{tabular}




\begin{tabular}{|c|l|c|c|c|c|}
\hline 17 & $\begin{array}{l}\text { Schools use an electronic network that links them to } \\
\text { parents. }\end{array}$ & 2.58 & 0.37 & 20 & medium \\
\hline 16 & $\begin{array}{l}\text { Schools use a technical system to collect information } \\
\text { on all school personnel. }\end{array}$ & 2.47 & 0.44 & 21 & medium \\
\hline 4 & $\begin{array}{l}\text { Parents are involved in the implementation of the } \\
\text { technical development process. }\end{array}$ & 2.29 & 0.56 & 22 & low \\
\hline 1 & $\begin{array}{l}\text { Parents are contacted by the school's technician when } \\
\text { there is a defect in the implementation of the electronic } \\
\text { lessons. }\end{array}$ & 2.28 & 0.38 & 23 & low \\
\hline \multicolumn{2}{|}{ The whole } & 3.41 & 0.22 & medium \\
\hline
\end{tabular}

It is noted from Table (2) that the reality of the electronic technical facilities used in Arab schools in Israel from the parents' point of view came in medium degree, as the arithmetic average reached (3.41) with a standard deviation (0.22), and this result means that there are some obstacles faced by Arab school in providing electronic technical facilities. It is noted that item (9) came in the first rank, which states that "Schools use a system to save and store data electronically", with a mean (4.22), and a standard deviation (0.29), which means that the Arab school in Israel interest in technical development, and the constant endeavor to take advantage of the facilities provided by modern digital technologies. Therefore, Schools use a system to save and store data electronically. This finding is agree with the findings of Siron, Wibowo, \& Narmaditya (2020) study which indicate that the students' intention in using e-learning was determined by several variables, including perceived enjoyment, students experience, computer anxiety, and perceived self-efficacy. These findings also confirm that both perceived ease of use and perceived usefulness can explain the students' intention in utilizing e-learning. The results provide an implication toward the importance of understanding the factors of e-learning adoption and how students can perceive e-learning as the response of the COVID-19 pandemic, And with the findings of Hariyanto, Triyono \& Kohler (2020) study which indicates at first the usability of the adaptive e-learning system for the students was well accepted in all aspects of usability. Next, the multiple linear regression result showed that the variables usefulness, ease of use, and ease of learning simultaneously influence satisfaction. Lastly, the regression results also revealed that the variables usefulness and ease of use partially influence satisfaction while the variable ease of learning does not, and with the findings of the study of Mailizar, Maulina \& Bruce (2020) that noted that student level barrier had the highest impact on e-learning use. In addition, the student level barrier showed strong positive correlation with the school level barrier and curriculum level barrier.

Item (1) which states that "Parents are contacted by the school's technician when there is a defect in the implementation of the electronic lessons" came in the last rank, with an arithmetic mean (2.28) and a standard deviation (0.38), and in a low degree, this result means that the student cannot evaluate his colleague and benefit from the errors, and this result may be attributed to the fact that computerized curricula do not allow "peer evaluation," and evaluation is limited to the evaluation performed by the teacher only, which is done electronically through the available electronic platforms. This result means that parents cannot communicate directly and effectively with the school administration or teachers when there is a defect in the implementation of electronic lessons, and this result may be attributed to the fact that electronic curricula are implemented asynchronously, which weakens the opportunity for direct online communication between the teacher and his students. This finding is agree with the findings of Innocent \& Masue (2020) study that revealed that there is limited applicability of e learning in the three HLIs studied. The inadequate applicability of E-learning is attributed to poor attitude, lack of skills among the users and insufficient ICT infrastructure, and with the findings of the study of Shdaifat, Shdaifat $\&$ Khateeb (2020) which revealed that the severity of the challenges associated with using E-Learning applications in this regard is high.

\section{Recommendations and suggestions}

In the light of the findings of this study, the researcher recommends the following:

- Adopting the provision of the necessary financial support by the university administration to provide the latest educational programs.

- Involving Parents in the implementation of the technical development process by the school administration.

- Adopting new legislation that permitting parents to contact by the school's technician when there is a defect in the implementation of the electronic lessons.

- Adopting offering electronic software that enables peer evaluation.

- Conducting more studies aimed at investigating the reality of e-learning in other societies and comparing its results with the results of the current study. 


\section{References}

Akanbi, A. (2020), Availability and Utilization of E-Learning Facilities in the Teaching of Senior School Physics in Ilorin, Nigeria, Journal of Education and Learning, 14(3), pp. 331- 337.

Al-Kindi, A. (2018), the difficulties of electronic supervisory follow-up and methods to develop them from the viewpoint of the educational supervisors in the Sultanate of Oman, Journal of the Islamic University for Educational and Psychological Studies, 26 (2), 544-568.

Alqahtani, Y. \& Rajkhan, A. (2020), E-Learning Critical Success Factors during the COVID-19 Pandemic: A Comprehensive Analysis of E-Learning Managerial Perspectives, Education Sciences, Educ. Sci. 10(1), 116.

Al-Shammari, S. (2019), The effect of color coding of written text in an e-learning environment on developing writing skills among fourth-grade primary students, an unpublished master's thesis, Qassim University, Saudi Arabia.

Al-Sharqawi, J. (2015), Developing the concepts and skills of e-learning and education among students of the College of Education in the Sultanate of Oman. Journal of Education College, 28(1), 115 - 139.

Al-Shuraida, M. (2018), the Reality of Using the E-Learning Environment in the Jordanian Ministry of Education and the Development Requirements from Teachers' Viewpoint and Its Relation to Some Variables, Unpublished Master Thesis, University of Jordan, Jordan.

Apostolou, C. (2020), The Level of ICT Infrastructure as a Factor of ICT Integration in Greek High School Science Teaching, Electronic Journal of e-Learning, 18(6), pp. 562-574.

Bada, k., Asianzu, E. Lugemwa, B., Namataba, J. \& Milburga, A. (2020), An Empirical Study on E-Learning Uptake by Teaching Staff at Makerere University Business School, International Journal of Education and Development using Information and Communication Technology, 16, (2), pp. 188-206.

Bigirwa, J., Ndawula, S., Naluwemba, E. (2020), On-Line Quality Management a Precursor for Improving ELearning Adoption in Midwifery Schools in Uganda, International Journal of Educational Methodology, $6(2), 271-283$.

Borthwick, K. \& Plutino, A. (2020), Education 4.0 Revolution: Transformative Approaches to Language Teaching and Learning, Assessment and Campus Design, Edited by Kate Borthwick and Alessia Plutino, Published by Research-publishing.net, a not-for-profit association.

Canadian Teacher Magazine (2014). The Classroom Comes Alive with Smart Board. Canadian Teacher Magazine.com- Webmaster: Clayrose Internet Creatios.

Canadian Teacher Magazine (2014). The Classroom Comes Alive with Smart Board. Canadian Teacher Magazine.com- Webmaster: Clayrose Internet Creatios.

Desmond, Keegan. (1995), On Defining distance Education, Distance Education International perspectives. London: Coron Helm.

Erdugan, F. (2020), investigating readiness levels of sports science faculty students towards e-learning, African Educational Research Journal, (2), pp. 272-279.

Hariyanto, D., Triyono, M. \& Kohler, T. (2020), Usability Evaluation of Personalized Adaptive e-Learning System Using Use Questionnaire, Knowledge Management \& E-Learning, 12(1), 85-105.

Huang, R., Liu, D., Tlili, A., Yang, J. \& Wang, H. (2020), Handbook on Facilitating Flexible Learning During Educational Disruption: The Chinese Experience in Maintaining Undisrupted Learning in COVID-19 Outbreak. Beijing: Smart Learning Institute of Beijing Normal University.

Innocent, A. \& Masue, S. (2020), Applicability of E-Learning in Higher Learning Institutions in Tanzania, International Journal of Education and Development using Information and Communication Technology, 16(2), p. 242-249.

Ivanova, K. (2020), eLearning Informatics: From Automation of Educational Activities to Intelligent Solutions Building, Informatics in Education, 19(2), p257-282.

Jalali, A. (2011), Use of Podcasting as an Innovative Asynchronous E-Learning Tool for Students, US-China Education Review A 6 p741-748.

Khatib, Lotfi. (2013), Educational Technology and Self- Education. Amman: Wail Publishing House.

Mailizar, A., Maulina, S. \& Bruce, S. (2020), Secondary School Mathematics Teachers' Views on E-Learning Implementation Barriers during the COVID-19 Pandemic: The Case of Indonesia, URASIA Journal of Mathematics, Science and Technology Education, 16(7), 1305-8223.

Manyike, T. (2017), Postgraduate Supervision at an Open Distance E-Learning Institution in South Africa, South African Journal of Education, 37(2), 398- 411.

Meirovitz, T. \& Aran, S. (2020), An Investigation of Digital Thinking Skills in EFL Digital Instruction, Interdisciplinary Journal of e-Skills and Lifelong Learning,16(1), p19-41.

Olaniran, S. (2017), Assessing the utilization level of E-learning resources among ODL based pre-service teacher trainees, the Electronic Journal of E-learning, 15(5), pp. 384-394.

Olson, J., Codde, J., deMaagd, K., Tarkelson, E., Sinclair J., Yook, S. \& Egidio R. (2011). "n Analysis of e- 
Learning impacts \& best practices in developing countries - With reference to Secondary School Education in Tanzania". Information \& Communications Technology for Development. Michigan State University.

Qashmar, D. (2017), E-learning requirements in the university educational process, Journal of Humanities and Social Sciences Generation, 28 (1), 149-170.

Shaikh, A., Umrani, A., Jumani, A. \& Laghari, A. (2019). Technology enhanced learning: a digital timeline learning system for higher educational institutes. International Journal of Computer Science and Network Security, 19(10), 1-5

Shdaifat, S., Shdaifat, K. \& Khateeb, 1. (2020), The Reality of Using E-Learning Applications in Vocational Education Courses during COVID 19 Crisis from the Vocational Education Teachers' Perceptive in Jordan, International Education Studies, 13(10), 105 - 112.

Siron, Y., Wibowo, A. \& Narmaditya, B. (2020), Factors Affecting the Adoption of E-Learning in Indonesia: Lesson from COVID-19, Journal of Technology and Science Education, 10(2), p282-295.

WHO. (2020), Coronavirus disease (COVID-19) pandemic. 2020, from https://www.who.int. 